\title{
Effects of Food Traceability Applied in Fresh Vegetable Supply Chain in China
}

\author{
Yang $\mathrm{Xu}^{1}$, Feng Tan ${ }^{1, *}$, Sandra Turner ${ }^{2}$, Li Cheng ${ }^{1}$, Xiang Dong ${ }^{1}$ \\ ${ }^{1}$ Beijing University of Agriculture, Beijing, 102206, China \\ ${ }^{2}$ Harper Adams University, TF10 8NB, United Kingdom
}

\begin{abstract}
A unique traceable code can often be found on the label of high value fresh produces, such as organic, environmental friendly, and green fresh vegetables. Consumers are able to use the traceable code to search product information in a searching system. It has been found out from questionnaire survey that although high percentage of consumers think traceable code based searching system is an effective approach for getting information about food producing and product test, only limited number of consumer actually use the searching system. Also, number of consumers think is too expensive to buy traceable fresh vegetables. The results from sample test present the traceable fresh vegetable information in the searching system is very limit. The information about field history and product testing need to be added into the system, and government, media and companies need to encourage consumers to buy more traceable foods and to use the searching system more effectively.
\end{abstract}

Keywords-food traceability; fresh vegetable; supply chain; searching system.

\section{INTRODUCTION}

Food traceability (hear after "FT") is the ability to track any food through all stages of production, processing and distribution[1]. Identify the units and batches of all raw materials and products; understand transfer and movement details; an effective data connection system are three main features of FT [2]. On one hand, companies use FT to promoting supply chain management, ensure safety and quality of food and to distinguish the food quality attributes to their competitors [3]. On the other hand, FT can increase consumers' confidence on food quality and safety [4]. In order to make FT system work effectively, all members in food supply chain need to contribute their efforts.

Although FT well applied in developed countries, it only draw Chinese government's attention since 2002. Due to the benefits of adopting FT, it was assumed the system would be successful and widely promoted. However, it still develop at emerging stage in China, which mainly because limited promotion by governments and/or organizations, high price of traceable foods and consumers' knowledge limitations [57].

There are many science researches reported the technologies and applications of FT, however, not many researches test the authenticity, practicability and comprehensiveness of the traceability information, and the effect of FT applied in fresh vegetable supply chain in China [8-9].
The research used questionnaires to collect data in finding out the effects, and used obtainable samples to test the traceability information of traceable foods in China. These can fill the gap of the existing literatures.

\section{FoOd TRACEABILITY SYSTEM IN CHINA}

From 2000 to 2013, there are numbers of food safety accidents happened in China. China has realized the important of introducing FT since 2002. It has been found out the heavy metals level contain in green house grow vegetables did lower than open-filed grow vegetables [10]. It is useful for buyers to know the growing statutes of foods they buy. However, many influences has limited the development of FT in China. Firstly, government and relevant organizations did not make strong promotions on FT system, consumers have limited knowledge about it. Secondly, the education level of food buyers has limited the development of FT. Finally, the price of traceable foods is much higher than the ordinary product, which make consumers not willing to pay [5-7].

It has been found out from a survey that most consumers are concerned about the food quality and safety, but many of them do not know what is FT. Only $1.9 \%$ of consumers familiar with FT system and care about traceability information. The purchase of traceable food is strongly influenced by food price, $86.4 \%$ of consumers want to buy traceable food if regardless of prices, but this number drop to $46.6 \%$ when it connected to prices [11].

\section{RESEARCH METHODOLOGY}

In China, a unique traceable code is addressed on the label of fresh produces, especially organic/environmental friendly/green fresh produces. This code is mainly for buyers to find out growing information of the vegetable through a online terminal system. The system offers public service which allows producers to issue growing information for consumers' online checking with computers and/or from machines in supermarkets. The research use questionnaire and sample test to evaluate the effect of traceable code based traceability system applied in fresh vegetable supply chain in China. The questionnaire is designed for understanding the consumer attitudes towards the application of the system. The sample test is aimed to identify the effectiveness of the food traceability system. 945 valid questionnaires have been used in the data analysis, with a percentage of $51 \%$ male and $49 \%$ female interviewees joint. 148 obtainable samples of fresh vegetable products sold via supermarkets or farm 
markets have been collected for checking information presence in the food traceability system via each traceable code. SPSS software has been used for data analysis.

\section{FINDING AND DISCUSSION}

\section{A. Consumer recognition towards the traceable code} based searching system

The questionnaire survey results of consumer recognition towards the traceable code based searching system can be seen from Table I. High proportion of consumers think the Traceable code based searching system is an effective approach for getting information about food producing and product test

TABLE I. CONSUMER RECOGNITION TOWARDS TRACEABLE CODE BASED SYSTEM

\begin{tabular}{|c|c|c|c|c|c|}
\hline & \multicolumn{5}{|c|}{$\begin{array}{l}\text { Traceable code based searching system is an effective approach for getting } \\
\text { information about food producing and product test }\end{array}$} \\
\hline & Agree & Neither & Disagree & Unknown & Sum \\
\hline Count within all samples & 747 & 111 & 10 & 77 & 945 \\
\hline$\%$ within all samples & $79.0 \%$ & $11.7 \%$ & $1.1 \%$ & $8.1 \%$ & $100.0 \%$ \\
\hline Count within samples concern of produce freshness & 624 & 66 & 8 & 51 & 749 \\
\hline$\%$ within samples concern of produce freshness & $83.3 \%$ & $8.8 \%$ & $1.1 \%$ & $6.8 \%$ & $100.0 \%$ \\
\hline Count within samples concern of food hygiene and safety & 522 & 79 & 8 & 28 & 637 \\
\hline$\%$ within samples concern of food hygiene and safety & $81.9 \%$ & $12.4 \%$ & $1.3 \%$ & $4.4 \%$ & $100.0 \%$ \\
\hline Count within samples concern of produce/expire date & 502 & 49 & 9 & 23 & 583 \\
\hline$\%$ within samples concern of produce/expire date & $86.1 \%$ & $8.4 \%$ & $1.5 \%$ & $3.9 \%$ & $100.0 \%$ \\
\hline Count within samples concern of growing information & 116 & 19 & 0 & 4 & 139 \\
\hline$\%$ within samples concern of growing information & $83.5 \%$ & $13.7 \%$ & $0.0 \%$ & $2.9 \%$ & $100.0 \%$ \\
\hline
\end{tabular}

B. Attraction of traceable vegetable

techniques. Consumers' expectations would be increased

Food traceability is an approach for food safety management through supply chain. However, the cost of the when they spent high cost. The survey (Table II) indicated that the system has not achieved consumers' expectations. system is high, which cause by offering the food traceability

TABLE II. PURChASE EXPECTATION * PURChASE REFUSAL CROSS TABULATION

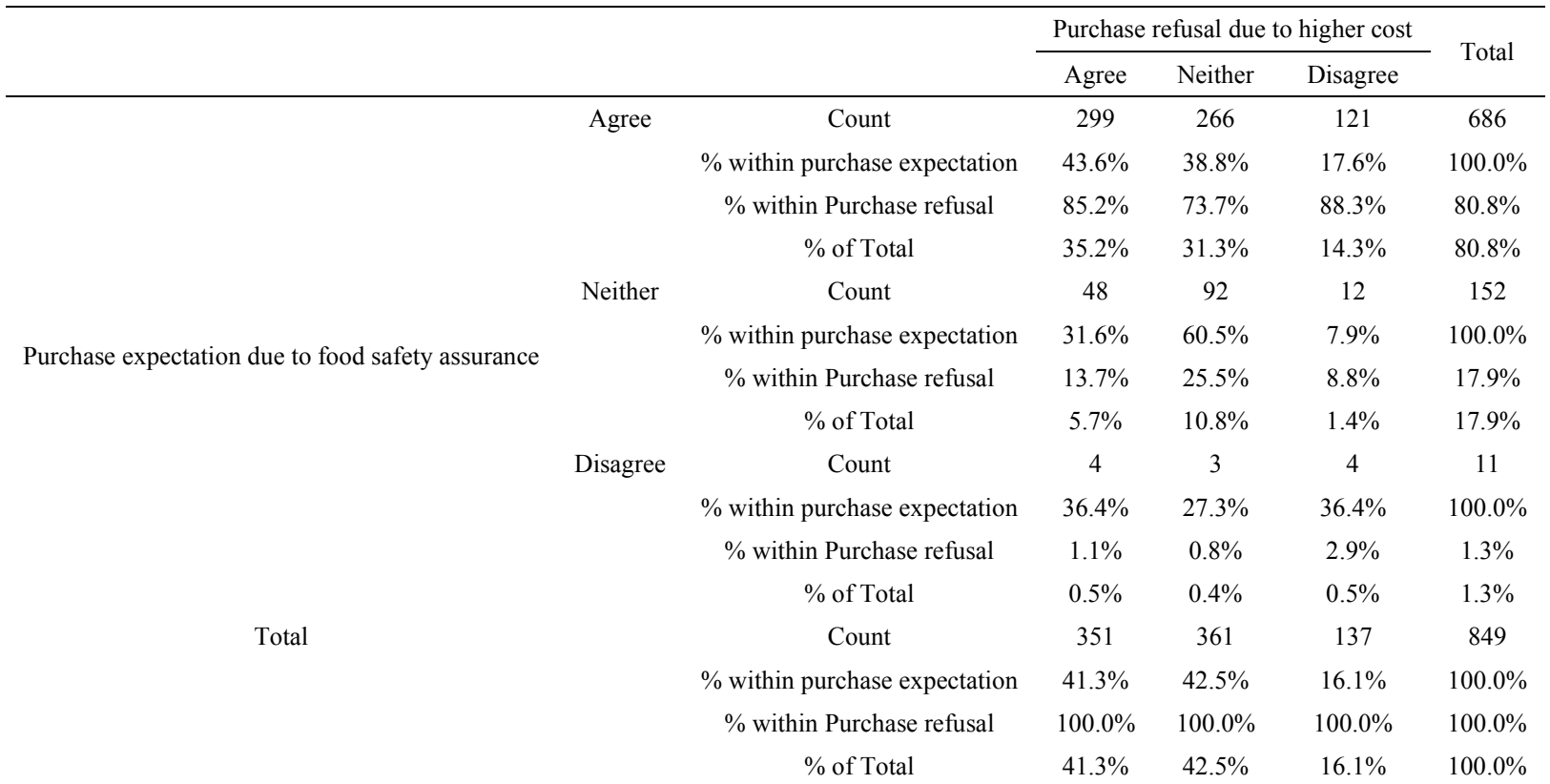

\section{Use of searching system via traceable code}

It can be seen from the following Table III, the use rate of the searching system is very low. Although there are many channels for consumer to know the searching system, many consumers who purchased traceable foods but not search frequently, only $2.7 \%$ interviewees often use traceable code to search information via searching system. This indicated that the promotions are inadequate to 
encourage and guide consumers in using the searching system.

TABLE III. THE USE OF SEARCHING SYSTEM

\begin{tabular}{|c|c|c|c|c|c|}
\hline & \multicolumn{5}{|c|}{$\begin{array}{c}\text { Activity of search information in food traceability system after purchase of traceable } \\
\text { produce }\end{array}$} \\
\hline & No purchase & No search & Some search & Often search & Sum \\
\hline Count within totals & 114 & 321 & 391 & 23 & 849 \\
\hline$\%$ within totals & $13.4 \%$ & $37.8 \%$ & $46.1 \%$ & $2.7 \%$ & $100.0 \%$ \\
\hline $\begin{array}{l}\text { Count within samples unaware of the } \\
\text { search system available to be used }\end{array}$ & 48 & 52 & 0 & 0 & 100 \\
\hline $\begin{array}{l}\% \text { within samples unaware of the search } \\
\text { system available to be used }\end{array}$ & $48.0 \%$ & $52.0 \%$ & $0.0 \%$ & $0.0 \%$ & $100 \%$ \\
\hline $\begin{array}{l}\text { Count within samples aware of the search } \\
\text { system via newspaper/magazine }\end{array}$ & 28 & 146 & 220 & 12 & 406 \\
\hline $\begin{array}{l}\% \text { within samples aware of the search } \\
\text { system via newspaper/magazine }\end{array}$ & $6.9 \%$ & $36.0 \%$ & $54.2 \%$ & $3.0 \%$ & $100.0 \%$ \\
\hline $\begin{array}{l}\text { Count within samples aware of the search } \\
\text { system via television }\end{array}$ & 40 & 131 & 248 & 13 & 432 \\
\hline $\begin{array}{l}\% \text { within samples aware of the search } \\
\text { system via television }\end{array}$ & $9.3 \%$ & $30.3 \%$ & $57.4 \%$ & $3.0 \%$ & $1.0 \%$ \\
\hline $\begin{array}{l}\text { Count within samples aware of the search } \\
\text { system via internet }\end{array}$ & 14 & 115 & 238 & 14 & 381 \\
\hline $\begin{array}{l}\% \text { within samples aware of the search } \\
\text { system via internet }\end{array}$ & $3.7 \%$ & $30.2 \%$ & $62.5 \%$ & $3.7 \%$ & $100.0 \%$ \\
\hline $\begin{array}{l}\text { Count within samples aware of the search } \\
\text { system via supermarket }\end{array}$ & 15 & 45 & 65 & 8 & 133 \\
\hline $\begin{array}{l}\% \text { within samples aware of the search } \\
\text { system via supermarket }\end{array}$ & $11.3 \%$ & $33.8 \%$ & $48.9 \%$ & $6.0 \%$ & $100.0 \%$ \\
\hline
\end{tabular}

D. Effectiveness of the searching system

Based on the sample test of the 148 available samples from market, researchers have tested each sample's traceable code in the searching system. It has been found out (Table 4) that the traceable information in the searching system is very limit for most samples. Except of $8 \%$ samples present the information of fertilizer using, for other samples, there are no information about field history and product testing. This can be one of the reasons why consumer undesired in using the searching system.

TABLE IV SAMPLE TESTING RESULTS OF TRACEABLE INFORMATION IN SEARCHING SYSTEM

\begin{tabular}{llcc}
\hline Type of information & Item & Number of sample & Proportion \\
\hline Basic information & Presence of product name appropriately & 129 & 148 \\
& Presence of producer name & 148 & $100.0 \%$ \\
& Presence of date of packaging & 88 & $100.0 \%$ \\
& Presence of Shelf-life & $58.7 \%$ & 12 \\
& Presence of Batch number & 0 & $0.0 \%$ \\
Field history information & Presence of planting time & 0 & 12 \\
& Presence of pesticide using & $0.0 \%$ & $0.0 \%$ \\
Product testing information & Presence of fertilizer using & $0.0 \%$ & 0 \\
& Presence of pollution of the environment information & $0.0 \%$ & $0.0 \%$ \\
\hline
\end{tabular}

\section{CONCLUSION AND RECOMMENDATIONS}

Consumers have realized there is a unique traceable code addressed with high value fresh produces in market. High proportion consumers believe the traceable code based searching system should be an effective approach for getting information about food producing and product test. However, not many consumers use the searching system. Consumers also think the cost of buying traceable fresh vegetables is high. The traceable information for fresh vegetable is very limit in the searching system. There nearly non information relate to field history and product testing for most products. Therefore, it is recommended the field history information and product testing information need to be added into the system. Government needs to educate consumers about the traceability system and traceable information; and to give supervision to the searching system in order to make sure the authenticity and comprehensiveness of the information in the system. Companies and growers can use wider medias to make consumers know the benefits of traceable foods, to encourage consumers to buy more traceable foods and use the searching system more effectively. For food safety concerns, it is essential to involve more detailed traceable products information in the system. 


\section{REFERENCES}

[1] Food standards. Food traceability. Food standards. Available from:http://www.foodstandards.gov.au/industry/safetystandards/trace ability/pages/default.aspx, 2012.

[2] FSA (Food Standard Agency). Traceability in the food chain a preliminary study. FSA. Available from: www.food.gov.uk/multimedia/pdfs/ traceabilityinth efoodchain.pdf, 2002.

[3] Golan, E, Krissoff, B, Kuchler, F, et al. Traceability in the U.S. food supply: Economic theory and industrial studies. Agricultural Economic Report Number 830, 2004.

[4] Opara, L.U. Traceability in agriculture and food supply chain: a review of basic concepts, technological implications, and future prospects. Food, Agriculture \& Environment, 1(1), pp. 101-106, 2003.

[5] Liu Fang, Qin Xiurong. Introduction to the status quo of China's food safety. Science and technology in western China, 7(17), pp.56, 2008.
[6] Liu Jin, Zhang Mingliang, Zhang Qian. Today's food safety situation and countermeasures. China's food hygiene and health, 2(6), pp.1-3, 2004.

[7] Zhang Chenghai. Food safety traceability technology and application. Beijing: China Zhijian Publishing House and China Standards Press, 2012.

[8] $\mathrm{Xu}$ Feng. The food traceability system will use the commodity bar code. China Quality Newspaper.13(1), pp. 87-88, 2007.

[9] Ye ChunLing, Zhang Bing, Wang Rui. The application of vegetable safty of traceability system, the design of traceability code. Food Science, 27(7), pp.26-29, 2007.

[10] Gao Ding. Assessing the health risk of heavy metals in vegetables to the general population in Beijing, China. Journal of Environmental Sciences, 21(12), pp. 1702-1709, 2009.

[11] Zhao Rong, Qiao Juan, Chen Yusheng. Consumer buying behavior of traceability of food research, based on the analysis of the Haidian district of Beijing consumer survey. Technology Economics, 28(1), pp.54-55, 2009. 